\title{
Modeling of human spinal column and simulation of spinal deformities
}

\author{
C. M. Gruescu*, A. Garaiman**, E. C. Lovasz*** \\ *University Politehnica Timisoara, Mihai Viteazu 1, 300222, Timisoara, Romania, E-mail: corina.gruescu@upt.ro \\ **University Politehnica Timisoara, Mihai Viteazu 1, 300222,Timisoara, Romania, E-mail: alice_garaiman@yahoo.com \\ ***University Politehnica Timisoara, Mihai Viteazu 1, 300222, Timisoara, Romania, E-mail: erwin.lovasz@upt.ro \\ cross'ref http://dx.doi.org/10.5755/j01.mech.21.3.8505
}

\section{Introduction}

Modeling and simulation is widely used in all domains as resourceful tools in design, enhancement, improving or forecasting behavior of different systems. A wide range of software is available to aid solving engineering problems. However, there are systems, such as the biological ones, to which modeling and simulation is a very difficult task. The difficulty originates in two essential features:

- human body parts are very irregularly shaped;

- anthropometrical normal data is very scattered, regarding age, sex, race, profession, local environment traits and so on.

Therefore, biological models are not yet developed on large scale even though they would be very useful in investigating and monitoring patients suffering of widespread diseases. However, there is an encouraging start in modeling different parts of human body, such as feet [1], arms [2], mobile bones of the head [3] etc. The purpose of modeling is either depicting abnormal anatomical shapes or designing of devices such as prosthesis.

The present work focuses on the class of spinal deformities, which are very common in now-days. Most individuals suffer of mild or severe spinal column deformities, such as scoliosis, lordosis, kyphosis or combinations of these. Deformities cause diminution of personal comfort and of physical or intellectual capacity of effort. When severe, deformities bring on large distortions of thorax shape and alteration of respiratory process. Such spinal diseases occur frequently at school-age population, due to incorrect posture and/or to improper desk design and less frequently to adult population, due to sedentary activities (teachers, librarians, IT specialists etc.). The elder popula- tion also suffers because of irreversible bone alteration. Plenty of statistics describe the prelevance of such diseases in different places of the world, taking into account a lot of aspects such as: age, sex, profession, life standard etc. [46].The studies emphasize very detailed the importance of identifying early stages of spinal deformities because of cautious prognostic and very high costs of treatment [7].

Engineering sciences offer a large series of equipments to investigate the human bone system. Among the methods of investigation in use, the most common are X-ray, CT or MR imaging, Moire topography, digital ultrasonic mapping and optical scanning [8-17]. The stating order of these methods is chronological regarding the implementation and inversely from invasive character standpoint.

Countries which develop long term healthcare programs always include spinal deformities among the main issues to investigate and monitor, especially to school children and persons involved in specific professional activities. The main problems in tracing and monitoring spinal deformities consist of:

- finding a quick and less invasive method of investigation;

- establishing a set of numerical parameters to describe completely the column's shape;

- storing of a large amount of data considering the big number of subjects in the database;

- accessing data and evaluating the evolution of patients.

In order to model the spinal column and simulate its behavior, considering a long-term monitoring of an extended sample of population, the following workflow was conceived (Fig. 1).

\begin{tabular}{|c|c|c|}
\hline $\begin{array}{l}\text { Target group of subjects: } \\
\text { - school children (different ages); } \\
\text { - computer operating persons; } \\
\text {-elder people; } \\
\text {-other groups of persons potentially } \\
\text { affected by spinal deformities. }\end{array}$ & $\begin{array}{c}\begin{array}{c}\text { Investigation } \\
\text { method }\end{array} \\
\text { Optical scanning }\end{array}$ & $\begin{array}{l}\text { Output format of the resultats: } \\
\text { - numerical; } \\
\text { - graphical 2D (projection of spine } \\
\text { onto sagital, frontal and transverse } \\
\text { plane); } \\
\text { - 3D flexible models. }\end{array}$ \\
\hline 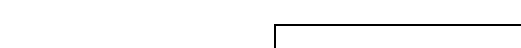 & & \\
\hline $\begin{array}{l}\text { Creation of a database } \\
\text { - access to chronological series of } \\
\text { numerical data and 3D models } \\
\text { - interactive facilities }\end{array}$ & & $\begin{array}{l}\text { Medical interpretation and } \\
\text { decision } \\
\text { adequate treatment (medical } \\
\text { gymnastics, physiotherapy, medical } \\
\text { corset, surgical correction etc.) }\end{array}$ \\
\hline
\end{tabular}

Fig. 1 Workflow of the biometric investigation and monitoring 
The text-boxes in figure 1 indicate the logical steps to follow from establishing the target group of subjects to physician's decision regarding the results of a complete, objective and non-invasive investigation. The lower text contains the concrete goals to fulfill at each step.

\section{Equipment and software to provide data for modeling}

As Fig. 1 shows the choice for the investigation method went to a totally non-invasive method, based on optical scanning.

A team of multidisciplinary specialists developed a diagnosis method based on the equipment offered by the Canadian Company InSpeck, specialized in 3D optical measurement digitizing using non - laser technology. The technical team chose to implement the system InSpeck 3D Halfbody, which needs three cameras (Fig. 2, a). The 3D cameras are Mega Capturor II digital cameras type (Fig. 2, b). The optical image acquired by each camera is turned into a signal, sent to a PC, where the software FAPS 5.5 (Fringe Acquisition and Processing Software) creates a 3D virtual model. The second software in the package - EM 5.5 (Editing and Merging) - allows complex processing of data. 3D digitization technique is meant to render a three-dimensional copy of the physical surface placed in front of the cameras.

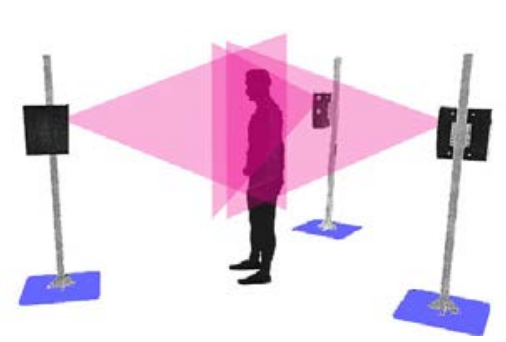

a

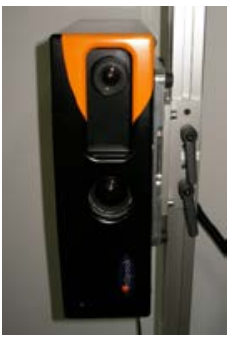

b
Fig. 2 a) Imaging in Halfbody configuration b) InSpeck 3D Mega Capturor II digital camera

The equipment InSpeck is an all-purpose imaging system, so that a special software, specific for the spinal column, was required in order to acquire data. A set of special markers was designed and manufactured to match the reference point of the vertebra - the spinous process. Figure 3 shows the position of 29 markers, attached to 23 vertebrae (C1...C7, T1...T12, L1...L5, S1...S3), shoulders (U1 and U2), scapulas (O1 and O2) and iliac crests (P1 and P2).

Determination of postural parameters, spinal characteristic distances and angles and, finally, global deformities need the knowledge of vertebrae coordinates along a zone as extended as possible. The practical measurements included a long segment of the spine comprising the vertebrae from C7 to S3. In Fig. 4, a is rendered an image of the vertebral spine. Different colors and symbols are assigned to cervical (C1...C7), thoracic (T1...T12), lumbar (L1...L5) and sacral (S1...S3) segments.

For a better description of posture and deformities, six supplemental markers picked coordinates of shoulders (U1 and U2), scapulas (O1 and O2) and iliac crests (P1 and P2).

As the equipment is able to pick 3D coordinates, the characteristic parameters of spine are defined within

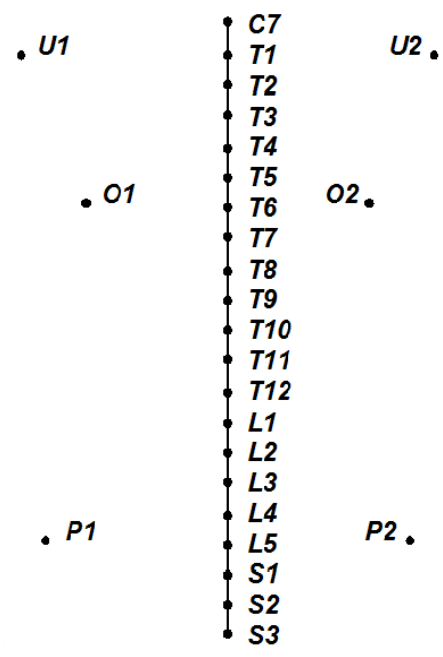

Fig. 3 Position of 29 markers to indicate the points where 3D coordinates are picked

one of the three anatomic planes (Fig. 4, b): xy -frontal plane, zy -sagital plane and $\mathrm{xz}$-transversal plane.

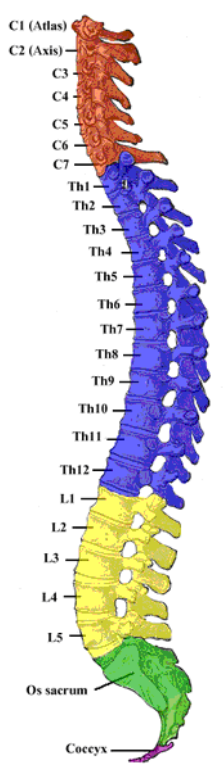

a

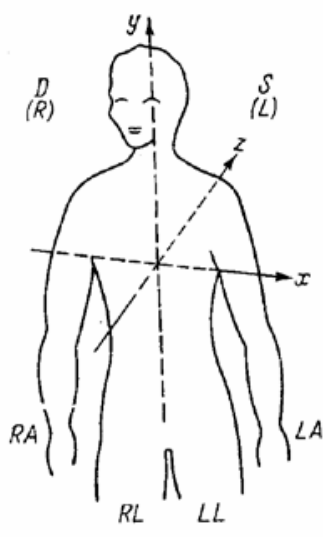

b
Fig. 4 a) View of vertebral column in sagital plane and symbols of vertebrae for the cervical, thoracic, lumbar and sacral zone; b) Position of anatomic planes defined to an orthogonal reference system xyz

Knowing 29 triplets of coordinates (x,y,z), a large series of parameters can be defined. In tables 1,2 and 3 are presented the significant parameters of the vertebral column, as proposed by the authors.

Beside the parameters of the vertebral column within the projection planes, the effective lengths in $3 \mathrm{D}$ measurement should be also considered: total length (from C7 to S3), thoracic length (from C7 to L1) and lumbar length (from L1 to L5).

The hardware configuration and the software facilities of FAPS 5.5 and EM 5.5, previously mentioned, were used to create an ASCII file, in *.txt format, containing numerical data of the 29 measuring points. The file is meant to be exported to an advanced processing program. 
Parameters in sagital plane (zy)

\begin{tabular}{|l|l|c|}
\hline Parameter & \multicolumn{1}{c|}{ Definition } \\
\hline $\begin{array}{l}\text { Total trunk } \\
\text { inclination }\end{array}$ & $\begin{array}{l}\text { angle between the vertebrae } \\
\text { line (C7 - L5) and the verti- } \\
\text { cal axis containing C7 }\end{array}$ \\
\hline $\begin{array}{l}\text { Thoracic } \\
\text { kyphosis }\end{array}$ & $\begin{array}{l}\text { angle between the vertebrae } \\
\text { line (C7 - T1) and vertebrae }\end{array}$ & $\begin{array}{l}\text { line (T12 - L1) } \\
\text { line (L1 -L2) and vertebrae } \\
\text { line (L5 - S1) } \\
\text { lordosis }\end{array}$ \\
\hline Sacral angle & $\begin{array}{l}\text { line (S1 - S3) and the verti- } \\
\text { cal line containing C7 }\end{array}$
\end{tabular}

Table 2

Parameters in frontal plane (xy)

\begin{tabular}{|c|c|c|}
\hline Parameter & Definition & Scheme \\
\hline $\begin{array}{l}\text { Pelvic } \\
\text { obliquity }\end{array}$ & $\begin{array}{l}\text { angle between pel- } \\
\text { vic line (P1 - P2) } \\
\text { and a horizontal line }\end{array}$ & $P 1 \quad T_{\alpha}$ \\
\hline $\begin{array}{l}\text { Shoulder } \\
\text { obliquity }\end{array}$ & $\begin{array}{l}\text { angle between } \\
\text { shoulders line (U1 - } \\
\text { U2) and a horizontal } \\
\text { line }\end{array}$ & U1 \\
\hline $\begin{array}{l}\text { Scapula } \\
\text { distance } \\
\text { right }\end{array}$ & $\begin{array}{l}\text { distance between } \\
\text { the top of the right } \\
\text { scapula and the } \\
\text { scapulas line pro- } \\
\text { jected along y - axis }\end{array}$ & iे|l \\
\hline $\begin{array}{l}\text { Scapula } \\
\text { distance left }\end{array}$ & $\begin{array}{l}\text { distance between } \\
\text { the top of the left } \\
\text { scapula and the } \\
\text { scapulas line pro- } \\
\text { jected along y - axis }\end{array}$ & 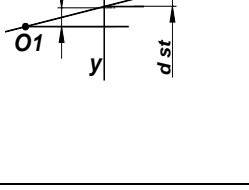 \\
\hline $\begin{array}{l}\text { Right scoli- } \\
\text { otic defor- } \\
\text { mation }\end{array}$ & $\begin{array}{l}\text { angle between ver- } \\
\text { tebrae line (C7 - } \\
\mathrm{T} 1) \text { and vertebrae } \\
\text { line (T11 - T12) }\end{array}$ & $\widehat{T}_{T 11}^{T 12}$ \\
\hline $\begin{array}{l}\text { Left scoliot- } \\
\text { ic defor- } \\
\text { mation }\end{array}$ & $\begin{array}{l}\text { angle between ver- } \\
\text { tebrae line (T11 - } \\
\text { T12) and vertebrae } \\
\text { line (S1 - S3) }\end{array}$ & $\left\{\begin{array}{l}T 11 \\
T 12 \\
S 1 \\
S 3\end{array}\right.$ \\
\hline $\begin{array}{l}\text { Lateral in- } \\
\text { clination }\end{array}$ & $\begin{array}{l}\text { angle between ver- } \\
\text { tebrae line (C7 - } \\
\text { S1) and the vertical } \\
\text { line containing } C 7\end{array}$ & s1. \\
\hline Cobb angle & $\begin{array}{l}\text { angle between the } \\
\text { perpendiculars to } \\
\text { vertebrae line (C7 - } \\
\text { T1), respectively } \\
\text { line (L4 - L5) }\end{array}$ & $\begin{array}{c}T 1 \\
T 12\end{array}$ \\
\hline
\end{tabular}

Table 3

Parameters in transversal plane (xz)

\begin{tabular}{|c|c|c|}
\hline Parameter & Definition & Scheme \\
\hline $\begin{array}{l}\text { Pelvic } \\
\text { rotation }\end{array}$ & $\begin{array}{l}\text { angle between the } \\
\text { pelvic line (P1 - P2) } \\
\text { and scapulas line (O1 } \\
\text { - O2) }\end{array}$ & \begin{tabular}{l|l}
$P 1$ & $P 2$ \\
01 & $\alpha 2$
\end{tabular} \\
\hline
\end{tabular}

The newly developed program, written as Visual Basic Application, was designed aiming the following requirements:

- development of a data basis containing a minimum set of information about the patients. The information should be accessed selectively, using different filters and should allow introducing and saving new data;

- import of data (coordinates of vertebrae) from an *.xls file;

- $\quad$ automated processing of data in order to obtain 16 parameters of posture or deformity;

- numerical and graphical display of results;

- print of an investigation report containing complete information about the patient (personal characteristics - such as name, age, profession - numerical and graphical results of investigation and notices of the physician if necessary).

The graphical interface of the program, named INBIRE is presented in Fig. 5.

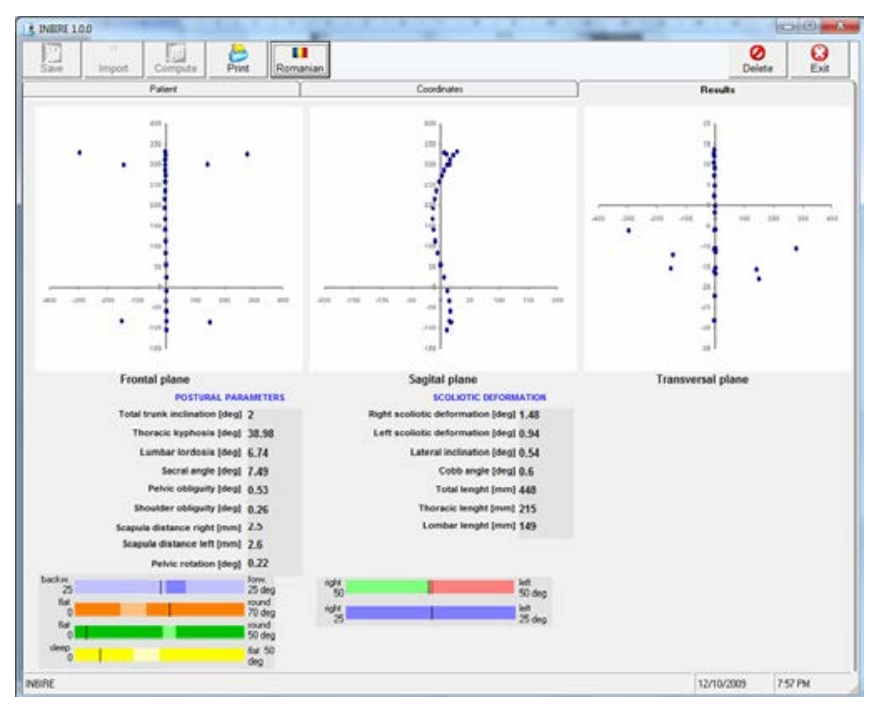

Fig. 5 Image of results’ display

\section{Modeling of vertebrae and simulation of column deformations}

Numerical parameters vary in large ranges and plane projections are not intuitive enough for the physician to establish a quick and correct diagnosis. It takes a great deal of time to correlate over 20 numerical characteristics even though graphical representations are partly helpful. The aim of a large scale investigation is both efficiency and precision. Thus, a 3D flexible model is welcomed.

Modeling of the spinal column is a difficult task so that the literature mentions only a few attempts to fulfill it [18-20]. Taking into account the specific problems occurring in modeling biological parts, it was conceived the workflow presented in Fig. 6. 
The program chosen to work in was 3Dmax. The general initial data consider the following elements:

- The spinal column is a complex biological structure, containing 33 - 34 vertebrae, 344 joints and 24 intervertebral discs.

- There are 5 distinct segments of the column: cervical (7 vertebrae), thoracic (12 vertebrae), lumbar (5 vertebrae), sacral (5 vertebrae stiffed together) and coccyx (45 rudimentary vertebrae).

- The column axis is 3D shaped curve: curvature angle of approximately $9^{\circ}$, cervical zone (C1-C7);

$>$ curvature angle of approximately $40^{\circ}$, thoracic zone (T1-T12);

$>$ curvature angle of approximately $57^{\circ}$, lumbar zone (L1-L5).

- Statistical height of a vertebra is $\sim 3 \mathrm{~cm}$.

- For each zone the shape of the vertebrae is different.

\begin{tabular}{|c|c|c|}
\hline $\begin{array}{l}\text { Model of specific } \\
\text { vertebra (cervical, } \\
\text { thoracic, lumbar, } \\
\text { sacral) }\end{array}$ & $\begin{array}{l}\text { Segments of the } \\
\text { column got from } \\
\text { arrays of similar } \\
\text { vertebrae (cervical, } \\
\text { thoracic, lumbar and } \\
\text { sacral zones) }\end{array}$ & $\begin{array}{c}\text { Spline } \\
\text { reprezenation of } \\
\text { column's axis based } \\
\text { on physiological } \\
\text { 3D curvatures and } \\
\text { angles } \\
\end{array}$ \\
\hline \multirow[t]{2}{*}{$\begin{array}{l}\text { Standard model of } \\
\text { the spinal column }\end{array}$} & $\begin{array}{l}\text { Personalized normal } \\
\text { model (by scaling the } \\
\text { standard model) }\end{array}$ & $\begin{array}{c}\text { Personalized model } \\
\text { with specific } \\
\text { deformities }\end{array}$ \\
\hline & $\begin{array}{c}\text { Storage in a database } \\
\text { and monitoring } \\
\text { evolution }\end{array}$ & \\
\hline
\end{tabular}

Fig. 6 General workflow of modeling the spinal column

Each type of vertebra was created starting from a regular shape, namely a cylinder. The functions of the program, such as Cut, Chamfer, Extrude, Smooth, Scale etc., allowed modifying the primary shape until it attained a perfect match with the vertebrae described in Grey's Anatomy Atlas [21].

Fig. 7 contains a print screen from the process of modeling a thoracic vertebra, whereas Fig. 8 renders all types of vertebrae together with their adjacent discs. To make the models more realistic, colors and textures were assigned to all elements. Specific zones of the column were obtained by cloning the appropriate type of vertebra and disc, in the required number. The function Array aligned the vertebrae along a spline, drawn using the physiological curvatures. The result is a standard model of spinal column (Fig. 9).

Personalized models result using the coordinates got from the program INBIRE, to trace the spinal axis. Functions PathDeform and Modifiers allow relatively easy and fast editing of the standard model. Fig. 10 illustrates through zoomed areas a column deformed by scoliosis.
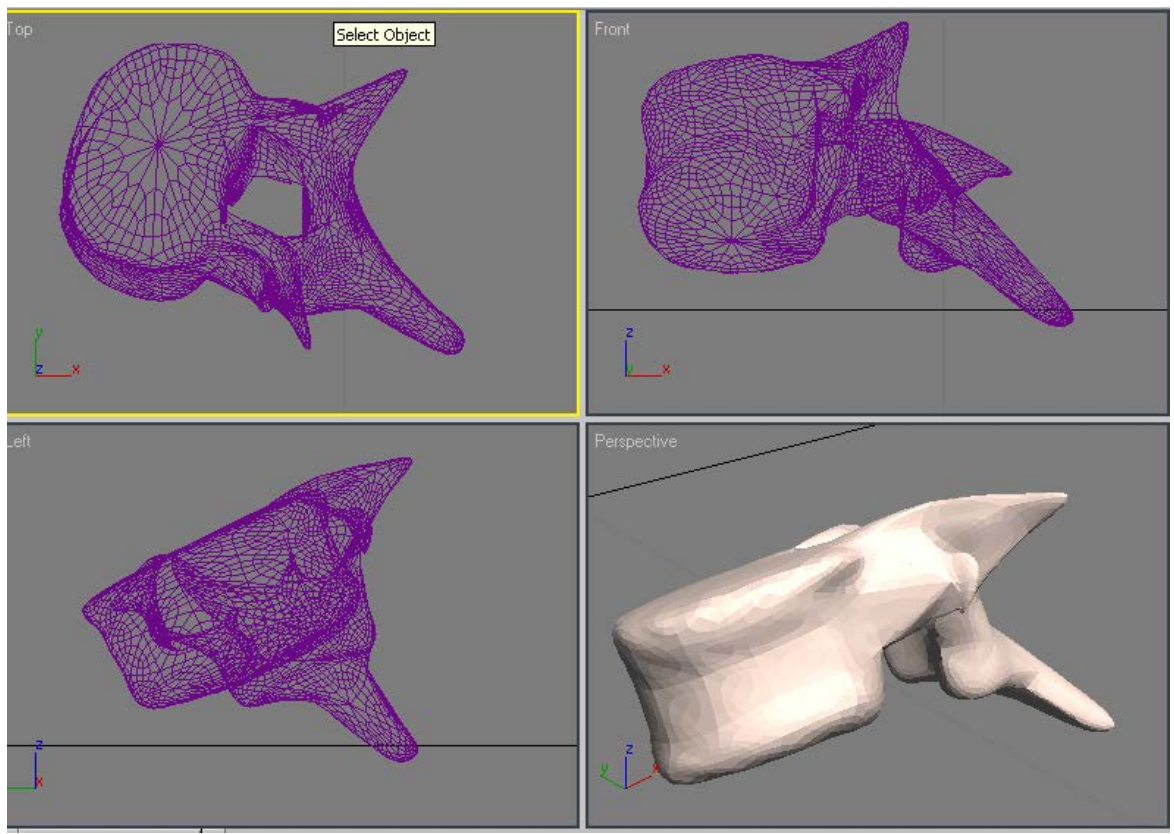

Fig. 7 Modeling a thoracic vertebra in processing 


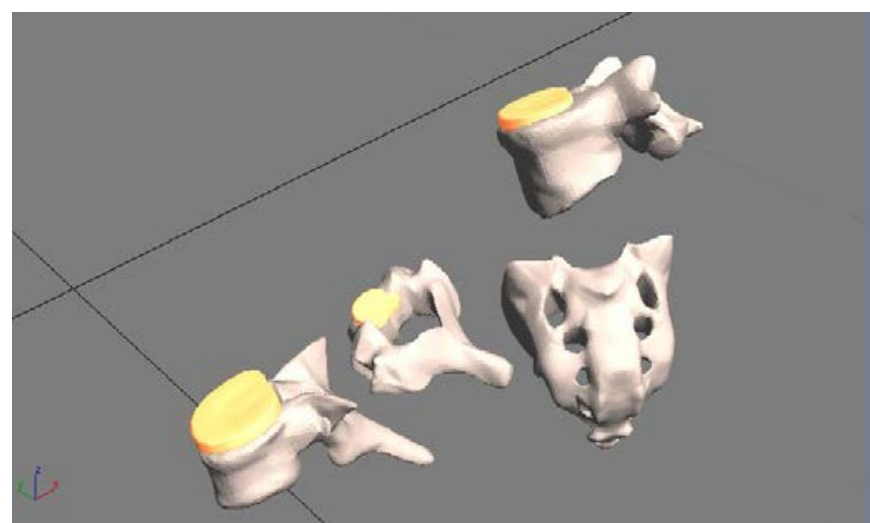

Fig. 8 Models of single cervical, thoracic, lumbar and sacral vertebrae with adjacent discs

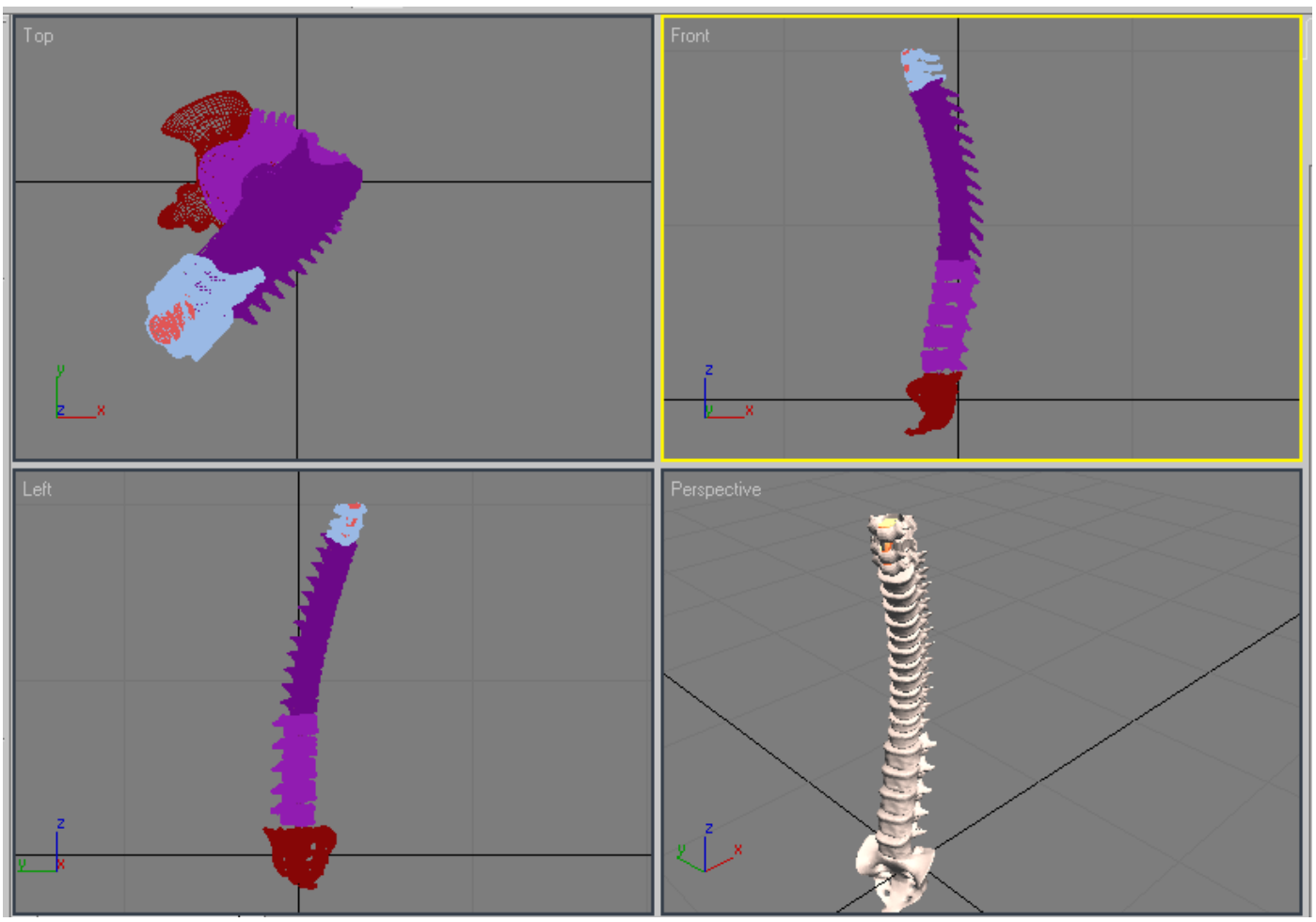

Fig. 9 Standard model of the spinal column
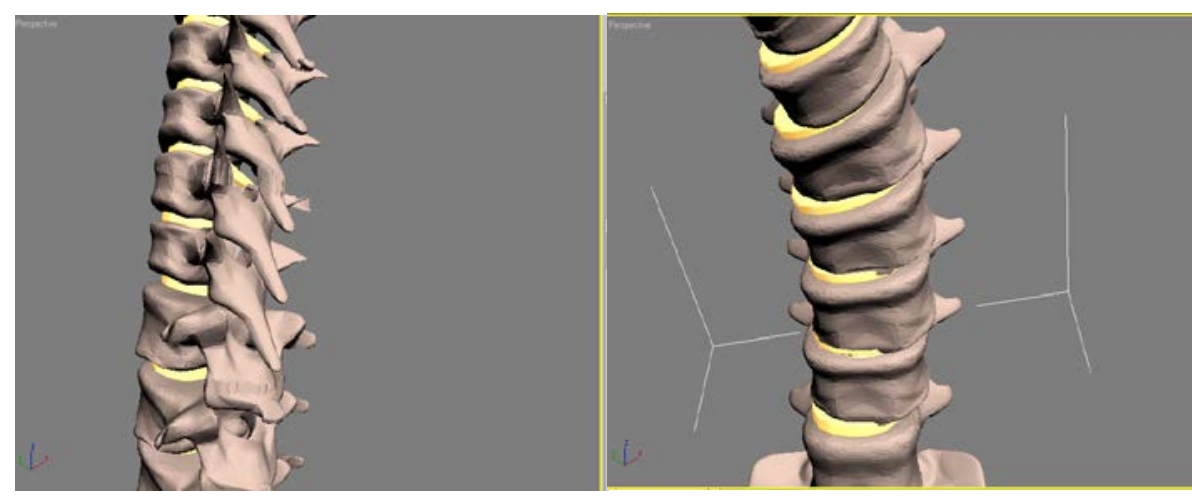

Fig. 10 Details of a column deformed by scoliosis

\section{Conclusions}

Modeling and simulating is difficult for human body parts, especially for mobile ones. The present paper described the implementation of a totally non-invasive method of investigation for the spinal column, which is frequently affected by deformities. A large number of numerical parameters were suggested for the description of the column's shape. A special software - INBIRE - was developed to work with the all purpose imaging system InSpeck. The program provides an interactive database and the facility to export data to the modeling program 3Dmax. Using anthropometrical data, the individual vertebrae and finally the entire column was modeled as a standard. The coordinates provided by INBIRE allow modeling of personalized spinal columns, which can be stored and used by 
physicians to monitor the evolution of the deformities.

The achievements of the research project contribute to development of local or national healthcare programs, bringing in numerical precision and efficiency in screening and monitoring spinal deformities, which are wide-spread, hard and costly to treat in advanced stages.

\section{Acknowledgements}

The present research work was possible with the support of the Biometric Investigations Laboratory at the University Politehnica Timisoara, which was developed within the national grant CEEX-88 INBIRE (2006 - 2008).

\section{References}

1. Pauk J.; Griškevičius J. 2011. Ground reaction force and support moment in typical and flat-feet children, Mechanika 17(1): 93-96. http://dx.doi.org/10.5755/j01.mech.17.1.209.

2. Vechet S.; Krejs J. 2009. Hydraulic arm modeling via matlab simhydraulics, Engineering Mechanics 16(4): 287-296.

3. Gąska D.; Kijak E.; Lipski T.; Margielewicz J. 2012. Numerical modelling of human masticatory organ kinematics, Mechanika 18(4): 447-452. http://dx.doi.org/10.5755/j01.mech.18.4.2327.

4. Milenkovic, S.; Kocijancic, R.; Belojevic, G. 2004. Left handedness and spine deformities in early adolescence, European Journal of Epidemiology. Springer Verlag. 19(10): 969-972. http://dx.doi.org/10.1007/s10654-004-4340-6.

5. Oxborrow, N.J. 2000. Assessing the child with scoliosis: the role of surface topography, Arch. Disease in Childhood 83: 453-455. http://dx.doi.org/10.1136/adc.83.5.453.

6. $* * *$ The Burden of Musculoskeletal Diseases in United States, on http://www.boneandjointburden.org, last accessed Oct. 2012.

7. Birchall, D.; Hughes, D.G.; Robinson, L. et al. 1999. Analysis of intravertebral axial rotation in adolescent idiopathic scoliosis using three-dimensional MRI, Research into Spinal Deformities 59: 61-64.

8. Chernukha, K.; Daffner, R.H.; Reigel, D. 1998. Lumbar Lordosis Measurement: A New Method Versus Cobb Technique, Spine 23(1): 74-79. http://dx.doi.org/10.1097/00007632-199801010-00016.

9. Friedrichs, A.; Kletzin, U. 2002. Entwicklung intelligenter mobiler Systeme zur Langzeiterfassung von Körperdaten. Proc. 47. Wissenschaftliches Kolloquium, TU Ilmenau. 11-12.

10. Lam, G.; Hill, D.; Le, L.; Raso, J.; Lou, E. 2008. Vertebral rotation measurement: a summary and comparison of common radiographic and CT methods, Scoliosis 3(1): 16 .

http://dx.doi.org/10.1186/1748-7161-3-16.

11. Lovasz, E.C.; Mateas, M.; Vilmos, F. 2003. Geometric Determination of the Human Spine in 3D. Proc. Inter-Ing. Conference 2003. Tg.-Mures. 131-137.

12. Lovasz, E.C.; Mateaş, M.; Micea, M. 2005. Determination of the Human Spine Geometry with CCDcameras. Proc. of the Scientific Reunion of the Special Program of the Alexander von Humboldt. Timişoara. 2: 292-295.
13. Mayer, T.G.; $\quad$ Tencer, A.F.; $\quad$ Kristoferson, S.; Mooney, V. 1984. Use of noninvasive techniques for quantification of spinal range-of-motion in normal subjects and chronic low-back dysfunction patients, Spine 9(6): 588-595.

http://dx.doi.org/10.1097/00007632-198409000-00009.

14. Pearsall, D.J.; Reid, J.G.; Hedden, D.M. 1992. Comparison of three noninvasive methods for measuring scoliosis, Physical Therapy 72(9): 648-657.

15. Zsidai, A.; Kocsis, L. 2001. Ultrasound-based spinal column examination systems, Facta Universitatis Budapest. Series Physical Education and Sport 1(8): 0112.

16. Mateaş, M.; Văcărescu, V.; Lovasz, E.C.; Nemes, I.D.; Micea. M.M. 2007. About a new method for the $3 \mathrm{D}$ determination of the human spine geometry. Proc. of the XII-th IFToMM internaţional Congress. Besancon. (1): 300-305.

17. Văcărescu, V.; Lovasz, E.C.; Văcărescu, C.; Mărgineanu, D. 2008. The method for the evaluation of spinal column posture. Proc. of the 19-th International DAAAM Symposium Intelligent Manufacturing \& Automation. 1435-1436.

18. Breglia, D.P. 2006. Generation of a 3d parametric solid model of the human spine using antrophomorphic parameters. Doctorate thesis. Faculty of Engeneering and Tehnology. Ohio University.

19. Benameur, S. Reconstruction 3d biplanaire non supervisée de la colonne vertébrale et de la cage thoracique scoliotiques par modèles statistiques. Doctorate Thesis. École de Technologie Supérieure Montréal.

20. Liu, J. 2001. A two-dimensional human spine simulation and threedimensional spine model construction. Doctorate Thesis. University of Florida.

21. ***2005. Grey's Anatomy, 39th edition. Elsevier Ltd. NY. ISBN 0443071683.

\section{C.M. Gruescu, A. Garaiman, E.C. Lovasz}

\section{MODELING OF HUMAN SPINAL COLUMN AND SIMULATION OF SPINAL DEFORMITIES}

S u m m a r y

The paper presents the implementation of a totally non-invasive method of investigation for the spinal column, which is frequently affected by deformities. The equipment InSpeck (an all-purpose imaging system) is used as totally non-invasive investigation equipment. Specific software is developed to write information in an interactive database and to compute 16 numerical parameters, describing the column's shape, respectively the human posture. Data exported from the database allows modeling of personalized spinal columns, by means of modifying a standard model generated in 3Dmax. The entire procedure is meant to help major healthcare programs, which involve screening and monitoring large samples of population.

Keywords: human column, deformities, modeling.

Received October 18, 2014

Accepted April 25, 2015 